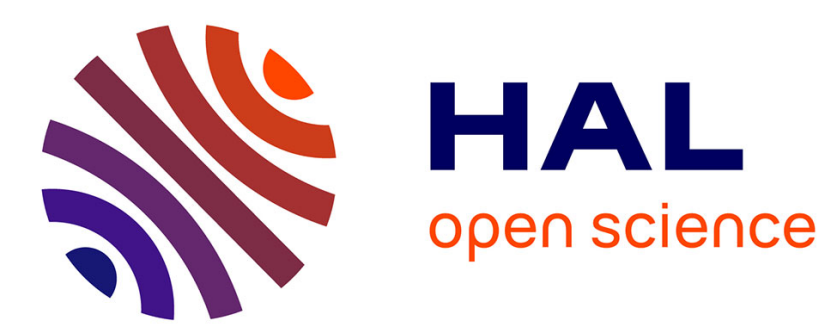

\title{
DFIG-Based Wind Turbine Fault Diagnosis Using a Specific Discrete Wavelet Transform
}

Elie Al-Ahmar, Mohamed Benbouzid, Yassine Amirat, Seifeddine Benelghali

\section{To cite this version:}

Elie Al-Ahmar, Mohamed Benbouzid, Yassine Amirat, Seifeddine Benelghali. DFIG-Based Wind Turbine Fault Diagnosis Using a Specific Discrete Wavelet Transform. ICEM'08, Sep 2008, Vilamoura, Portugal. pp.ID 1434. hal-00531286

\section{HAL Id: hal-00531286 https://hal.science/hal-00531286}

Submitted on 2 Nov 2010

HAL is a multi-disciplinary open access archive for the deposit and dissemination of scientific research documents, whether they are published or not. The documents may come from teaching and research institutions in France or abroad, or from public or private research centers.
L'archive ouverte pluridisciplinaire HAL, est destinée au dépôt et à la diffusion de documents scientifiques de niveau recherche, publiés ou non, émanant des établissements d'enseignement et de recherche français ou étrangers, des laboratoires publics ou privés. 


\title{
DFIG-Based Wind Turbine Fault Diagnosis Using a Specific Discrete Wavelet Transform
}

\author{
E. Al-Ahmar ${ }^{1,2}$, M.E.H. Benbouzid ${ }^{1}$, Y. Amirat ${ }^{1,3}$ and S.E. Ben Elghali ${ }^{1}$ \\ ${ }^{1}$ Laboratoire Brestois de Mécanique et des Systèmes (LBMS - EA 4325), University of Brest \\ IUT of Brest - Rue de Kergoat - CS 93837, 29238 Brest Cedex 03, France \\ E-mail: m.benbouzid@ieee.org \\ ${ }^{2}$ Faculty of Sciences and Computer Engineering, Holy Spirit University of Kaslik, BP 446, Jounieh, Lebanon \\ ${ }^{3}$ Electrical Engineering Department, University of Annaba, 23000 Annaba, Algeria.
}

\begin{abstract}
This paper deals with the investigation of a specific transient technique suitable for electrical and mechanical fault diagnosis in a DFIG-based wind turbine. The investigated technique is a combination of the Discrete Wavelet transform, statistics and the energy. Experimental investigations carried out on a 1.1-kW induction generator based test bench show that the proposed technique can unambiguously diagnose faults under transient conditions.
\end{abstract}

Index Terms-Wind turbine, Doubly-Fed Induction Generator (DFIG), Discrete Wavelet Transform (DWT), fault diagnosis.

\section{INTRODUCTION}

Wind energy conversion is the fastest-growing source of new electric generation in the world and it is expected to remain so for some time (Fig. 1). During the last two decades wind turbines have been developed in size from $20 \mathrm{~kW}$ to 2 MW, while even larger wind turbines already are being designed [1]. Due to the fact that wind generators are also inaccessible, since they are situated on extremely high towers over $20 \mathrm{~m}$ in height or in the sea (Fig. 2), there is a constant need for the reduction of operational and maintenance costs of wind generators which eliminates some of the difficulties due to accessibility problems and allows for early detection of mechanical and electrical faults preventing major component failures, facilitating a proactive response, minimizing downtime and maximizing productivity [2-5]. The most efficient way of reducing these costs would be to continuously monitor the condition of these generators. Figures 3 and 4 show respectively one of the most used wind turbine configuration (DFIG) and its main components [6-7].
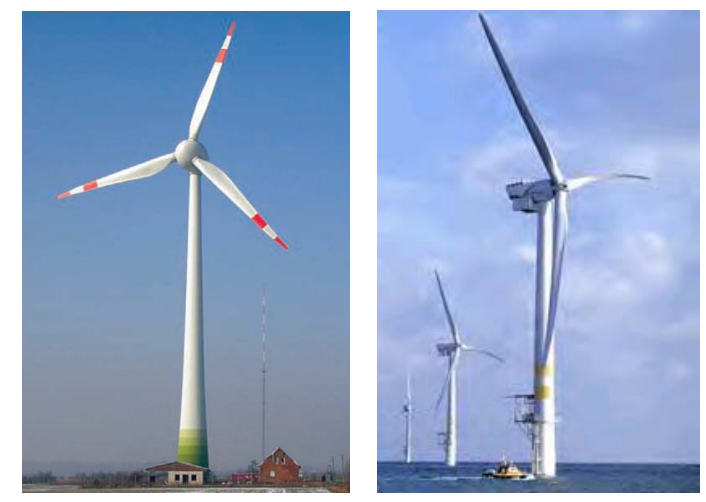

Fig. 2. Currently largest onshore wind turbine and offshore installations.

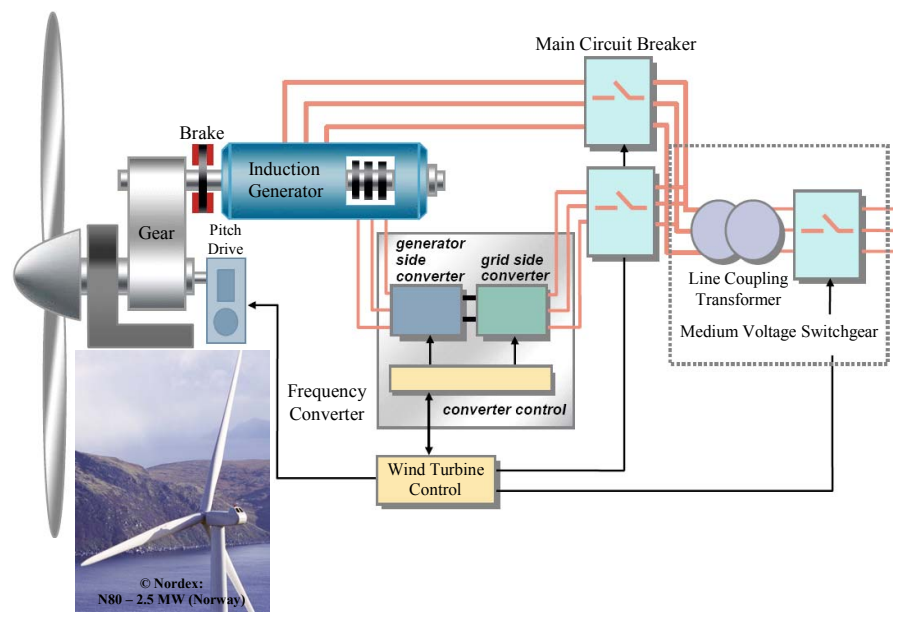

Fig. 3. Most used wind turbine configuration (with DFIG arrangement).

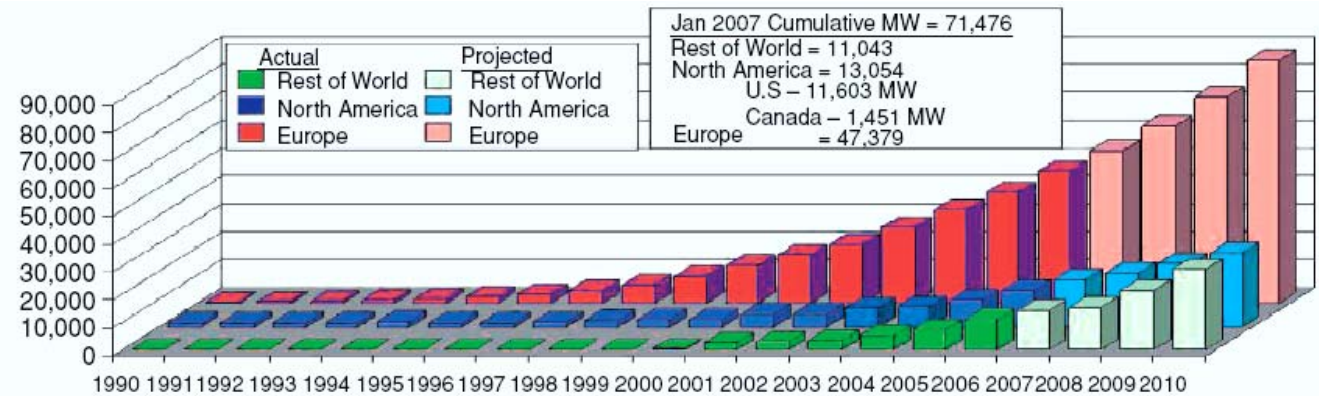

Fig. 1. Worldwide growth of wind energy installed capacity [1]. 


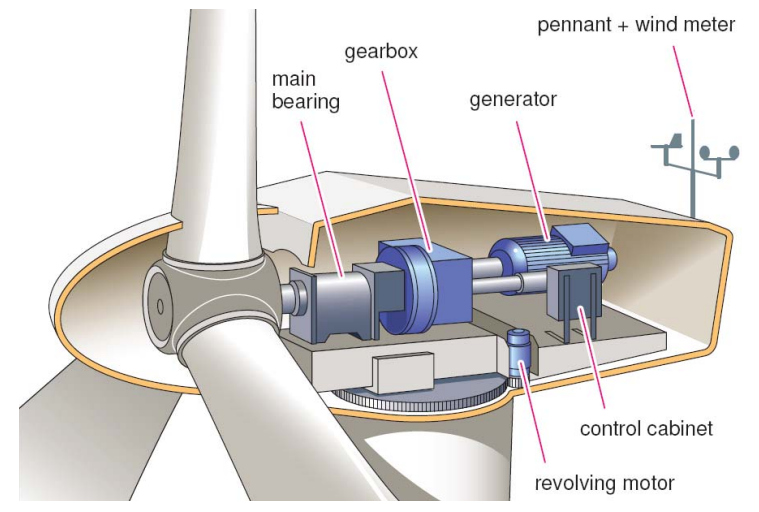

Fig. 4. Wind turbine nacelle cross-section.

Many techniques and tools are available and used to monitor the condition of induction machines. The most popular methods utilize the steady-state spectral components of the stator quantities [8-9]. These stator spectral components include voltage, current and power and are used to detect turn faults, broken rotor bars, bearing failures, air gap eccentricities [9-10]. However, the operation of wind generators is predominantly transient, therefore prompting the development of non-stationary techniques for fault detection such as DWT [11].

The objective of this paper is to develop and test a detection method for condition monitoring, suitably adapted for implementation in wind generator systems based on the DWT, the variance and the energy to detect failures under transient conditions. It is well-known that many electrical and mechanical faults in induction motors have a direct impact on the motor magnetic field. Indeed, they modulate it [12]. Moreover, it has been proven that failures in a mechanical drive train connected to an induction machine can be detected at the terminal of the machine [13-16]. In the case of wind turbine condition monitoring, a number of published work are based on the following hypothesis: It is possible to detect wind turbine drive train faults through the terminals of the associated generator [6], [17].

\section{THEORETICAL BACKGROUND AND WAVELET ANALYSIS}

One of the most important factors enabling a reduction of operational and maintenance costs of wind turbine, helping to avoid undesirable operating conditions and detecting component failures, is to provide wind generators with advanced condition monitoring and diagnosis system during operation (Fig. 5) [6], [17-18]. Autonomous online condition monitoring systems with integrated fault detection algorithms allow early warnings of mechanical and electrical faults to prevent major component failures. Side effect on other components can be reduced significantly. Many faults can be detected while the defective component is still operational. Therefore and due to the importance of condition monitoring and fault diagnosis in wind turbines (blades, drive trains, and generators); this section is intended to be as a tutorial overview describing different type of faults, their generated signatures, and their diagnostic schemes. It should be noted that the presented study is focused on DFIGs as they are the most used in wind turbines [17-18].

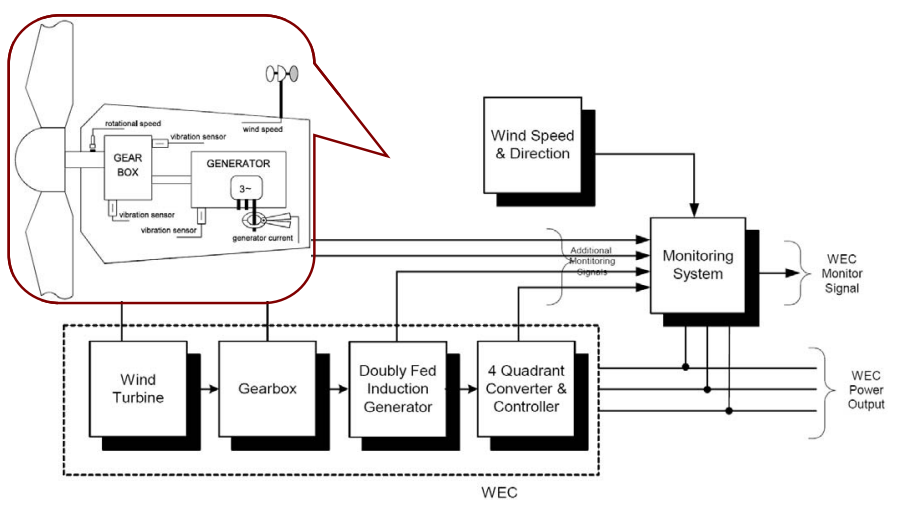

Fig. 5. Basic architecture for wind turbine condition monitoring and diagnosis.

\section{A. Wind Generators Failure Mode Analysis}

Many sources show that bearing faults and stator insulation breakdown causes the majority of machine failures. For small induction machines, the stator winding insulation degradation is one of the major causes [11], [21-23].

Induction generators can operate under asymmetrical stator and/or rotor-winding connections as described in [24]: Interturn fault resulting in the opening or shorting of one or more circuits of a stator phase winding, abnormal connection of the stator winding, inter-turn fault of a rotor phase winding and / or brushes, broken rotor bars or cracked rotor end-rings (cage rotor), static and/or dynamic air-gap irregularities, a rub between the rotor and the stator which can result in serious damage to the stator core and windings.

Faults in induction generators produce one or more of the following symptoms: unbalanced air-gap voltages and line currents, increased torque pulsation, decreased average torque, increased losses and reduction in efficiency, disturbances in the current, voltage and flux waveforms.

Failure surveys have reported that percentage failure by components in induction machines is typically: bearing related $(40 \%)$, stator related $(3 \%)$, rotor related $(10 \%)$ and others (12\%) [25-26].

\section{B. Fault Effects on Electromagnetic Signals}

Given the diversity of faults in induction generators, many methods were developed. These methods are classified into two categories: external or noninvasive methods that perform the analysis on the generator signals, without a priori knowledge, by advanced techniques of signal processing and internal methods that require a mathematical model of the system. Since all elaborated methods are, preferably, noninvasive, research turned to the analysis of the generator currents by advanced techniques of signal processing. These signal processing methods could be also classified in two categories: statistical and filtering approaches. The first category is based upon changes detection in statistical characteristics, such as the average, the variance and the moments of a higher order. The second category relies on electrical signals spectral analysis. It is often used for 
stationary analysis. However, some of the faults are characterized by non-stationary behaviors.

Current studies are more particularly related to methods adapted for non-stationary signals, such as time-frequency analysis and the wavelet decomposition [27-30].

Table 1 is given to illustrate faults effects (spectral fault signatures) on the stator current where $f_{s}$ is the supply frequency, $m=1,2,3 \ldots, s$ is the slip, $p$ is the number of pole pairs, $k=1,3,5 \ldots, f_{r}$ is the rotor frequency, $n_{b}$ is the bearing balls number, $f_{i, o}$ is the inner and the outer frequencies depending on the bearing characteristics.

\section{Wavelet Analysis}

During many years Fourier transform has been used for signal processing, since it is suitable for the study of a wide range of signals. Nevertheless, one of the shortcomings of the Fourier transform is that it does not give any information on the time at which a frequency component occurs [8]. Therefore, the approach of Short Time Fourier Transform (STFT) is used to give information on the time resolution of the signal spectrum [31]. Here a moving window is applied to the signal and the Fourier transform is applied within the window as the window is moved. As a disadvantage, several window lengths must be analyzed to determine the most appropriate choice. For analysis where a predetermined scaling may not be appropriate because of a wide range of dominant frequencies, a time-frequency localization method that is scale independent, such as wavelet analysis, should be employed. Thus, the Wavelet transform provides a time-frequency representation of the signal. It was developed to overcome the short coming of the STFT, which can also be used to analyze non-stationary signals [32]. While STFT gives a constant resolution at all frequencies, the Continuous Wavelet Transform (CWT) uses multi-resolution technique by which different frequencies are analyzed with different resolutions: at high frequencies, the CWT gives good time resolution and poor frequency resolution, while at low frequencies it provides good frequency resolution and poor time resolution [33]. The DWT, which is based on sub-band coding, is found to yield a fast computation of the CWT. It is easy to implement and reduces the computation time and the required resources.
Table 1. Fault signatures on stator current spectrum.

\begin{tabular}{|c|c|}
\hline Fault & Harmonic component \\
\hline $\begin{array}{c}\text { Broken rotor bars } \\
\text { or cracked rotor end rings }\end{array}$ & $f_{\text {rotbar }}=f_{s}\left[k\left(\frac{1-s}{p}\right) \pm s\right.$ \\
\hline $\begin{array}{c}\text { Eccentricity } \\
\text { (static, dynamic, mixed) }\end{array}$ & $f_{e x c}=f_{s}\left[1 \pm m \frac{(1-s)}{p}\right.$ \\
\hline Bearing & $\begin{array}{l}f_{b r g}=f_{s} \pm k_{i, o} \\
\left\{\begin{array}{c}f_{o}=0.4 n_{b} f_{r} \\
f_{i}=0.6 n_{b} f_{r}\end{array}\right.\end{array}$ \\
\hline Misalignment & $f_{m i s}=f_{s} \pm k f_{r}$ \\
\hline
\end{tabular}

A signal $s(t)$ can be approximated using the DWT by [34]

$s(t)=\sum_{i} \alpha_{i}^{n} \phi_{i}^{n}(t)+\sum_{j=1}^{n} \sum_{i} \beta_{i}^{j} \psi_{i}^{j}(t)=a_{n}+d_{n}+\ldots+d_{1}$

Where $\alpha_{i}^{n}, \beta_{i}^{j}$ are respectively, the scaling and the wavelet coefficients, $\phi^{n}(t), \psi^{i}(t)$ are respectively the scaling function at level $n$ and the wavelet function at level $j, n$ is the decomposition level, $a_{n}$ is the approximation signal at level $n$ and $d_{j}$ is the detail signal at level $j$ [35-38].

The DWT is computed by successive low-pass and highpass filtering of the discrete time-domain signal. This is called the Mallat algorithm or sub-band coding algorithm. Its significance is in the manner it connects the continuous-time multi-resolution to discrete-time filters. Figure 6 shows the sub-band coding algorithm regarding the coefficients of the transform at the different levels according to Polikar description [39]. The original signal is denoted by the sequence $s[n]$, with $n=512$ samples and a sampling rate of $f$ samples/sec. The low-pass filter is denoted by LPF while the high-pass filter is denoted by HPF. At each level, the high-pass filter produces the detail information $d_{j}$, while the low-pass filter associated with scaling function produces coarse approximations $a_{n}$.

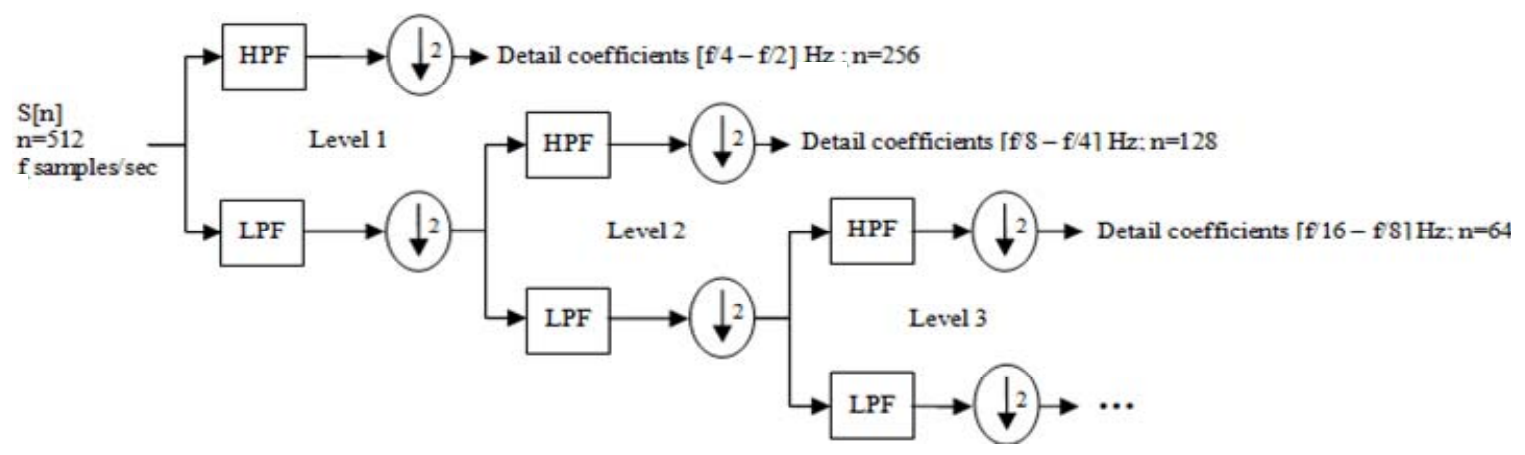

Fig. 6. The sub-band coding algorithm. 
At each decomposition level, the half band filters produce signals spanning only half the frequency band. This doubles the frequency resolution as the uncertainty in frequency is reduced by half. In accordance with Nyquist rule, a down-sampling by two for successive levels, halves the samples number of the previous level, with no information losses. This decimation by 2 halves the time resolution as the entire signal is now represented by only half of the samples number. Thus, while the half band low-pass filtering removes half of the frequencies and thus halves the resolution, the decimation by 2 doubles the scale. With this approach, the time resolution becomes arbitrarily good at high frequencies, while the frequency resolution becomes arbitrarily good at low frequencies.

If $f_{s}$ (samples/sec) is the sampling rate used for capturing $s(t)$, the detail $d_{i}$ contains the information concerning the signal components whose frequencies are included in the interval $\left[2^{-(j}\right.$ ${ }^{+1)} f_{s}, 2^{-j} f_{s}$. The approximation signal $a_{n}$ includes the low frequency components of the signal, belonging to the interval $\left[0,2^{-(n+1)} f_{s}\right]$. This filtering process performed in the DWT is shown in Fig. 7 [37]. It can be noticed that a certain overlap between bands due to the non-ideal wavelet filter characteristics, leading then to the aliasing problem: the Nyquist criteria is violated and frequency components above or below the cut-off frequency of the filter are aliased into the wrong sub-band [40]. This phenomenon causes what is known as shift-variance [41].

It should be noted that the above described DWT decomposition is proposed to be applied for transient current leading to a set of approximations and details signals. The analysis of these signals can allow the detection of some patterns caused by different type of failures.

\section{EXPERIMENTAL TESTS}

The aim of the present section is to apply and test a noninvasive monitoring technique, implemented under Matlab $^{\circledR}$, for the detection of failures in wind turbine induction generators, and to elaborate a comparative study among three types of wavelets to identify the characteristic pattern and the suitability of each one regarding different types of failures.

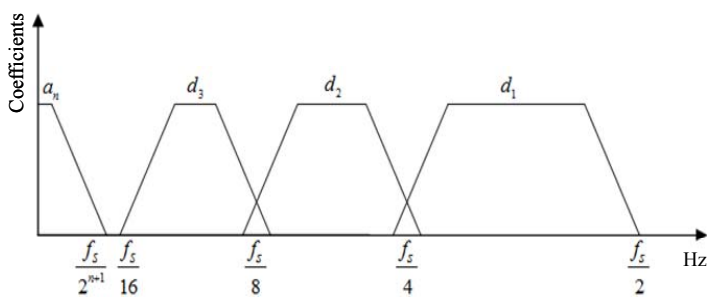

Fig. 7. Filtering performed with Mallat algorithm (DWT).

\section{A. Description of the Experimental System}

The experimental tests were carried out on an experimental setup located at the "CETIM" (Centre Technique des Industries Mécaniques, Senlis, France). The setup, which is depicted by Fig.8, consists in a 1.1-kW / 400-V / 50-Hz two pole pair induction generator. It spins a crane by the intermediate of a gearbox with a ratio of 77 and is loaded by a DC motor. A thread rolled up on the drum pulls the load in rotation following two modes: rising and descent modes. For measurement purposes, the setup is equipped with the following sensors: three current sensors (supply currents), two speed sensors (drum and shaft speeds), two torque sensors (torque instantaneous value and lifting torque). Moreover, multiple vibration sensors are installed on the generator as shown in Fig. 8.

The experimental setup is able to handle several types of mechanical failures. In the proposed study, the carried out failure is a one very specific to a wind turbine operation. It consists in the load collision with $50 \%$ severity of the nominal load that emulates the increase of the wind speed for a wind turbine. For this emulation, tests are realized with several loads and speeds. The load collision phenomenon is initiated after approximately 8 -sec of normal operation. The phenomenon remains for a duration of 20 -sec then the induction generator returns to its normal operation mode. It should be mentioned that the signal sampling frequency is $25 \mathrm{kHz}$.

\section{B. Experimental Results Analysis}

First, load collision phenomenon signatures are extracted from the supply currents. Figure 9 presents the time representation between 0 and 40 -sec for a nominal operation mode (Fig. 9a) and a signal containing a load collision which is in our case $50 \%$ load collision of the nominal load (Fig. 9b).

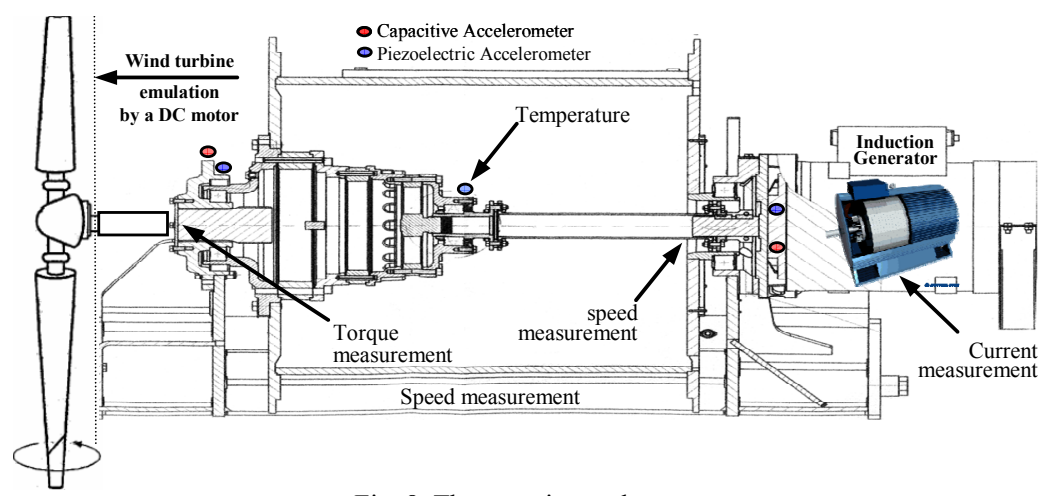

Fig. 8. The experimental setup. 
In this case, one should notice the influence of the load abrupt increase on the stator current. During the appearance of the fault, the current experiences an oscillatory period then it stabilizes with increased current amplitude. From Fig. 9b, it is also deduced that after the collision phenomenon, the stator current amplitude returns to its normal level after a transitory period.

Since previous detection methodologies have weakness during system transients, DWT analysis is therefore proposed to produce a similar analogy to that of the steady-state case. The used methodology starts with an eight levels DWT decomposition of non-stationary signals into both detail and approximate coefficients at different scales using Haar (db1), Daubechies of order 5 (db5) and dmeyer (dmey) as mother wavelets [34]. The time representation of the eight detail and approximation decomposition levels for healthy current signal and with $50 \%$ load collision defect, show clearly that the fault signature can be extracted from the generated eight detail and approximate signals and specifically in detail (d8) and approximate (a8) signals. It is also noticed a clear fault detection at $t=8$-sec as shown in Fig. 10.

As a second step and in order to make a comparison and to investigate which wavelet form is the most reliable in detecting load collision faults, it has been defined several classification or detection criterions that denote the increase in amplitude of several parameters according to their values in nominal induction generator operation mode. Indeed, it has been investigated the variance and the energy values detection criterion that respectively denotes the stator current variance and energy values increase in amplitude when load collisions occur. These investigations are carried out to determine the most reliable wavelets for the detection of faults in wind turbines (load collision in our case).

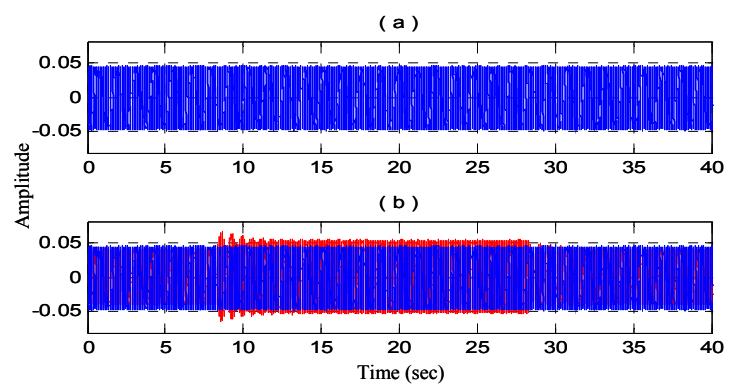

Fig. 9. Stator current time representation:

(a) Nominal operation mode, (b) With 50\% load collision.

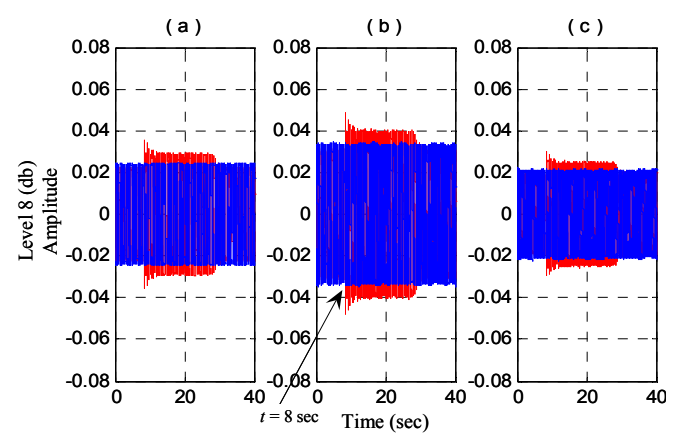

Fig. 10. Time representation of the $8^{\text {th }}$ detail decomposition level of the stator current in case of $50 \%$ load collision phenomenon using: (a) db1, (b)db5, and (c) dmey wavelets.
Figures 11 and 12 respectively show the variance and the energy detection criterion applied to the eight levels of the stator current wavelet decomposition as a function of the wavelet form for the $50 \%$ load collision. It can be noticed that, using these two criterions, a clear detection of load collision is observed at the $8^{\text {th }}$ level of decomposition. Moreover, regarding the obtained results one can deduce that the chosen detection criterions roughly do not depend on the wavelet form and their values can be easily used for the wind turbine operation mode quantification. While the results in Fig. 13 show that it is convenient to use the db1 wavelet form for the decomposition if the variance is used as a criterion and that the dmey form gives the most pronounced value of the energy criterion, next comes the $\mathrm{db} 5$ form, and last the $\mathrm{db} 1$ form.

\section{CONCLUSIONS}

This paper dealt with condition monitoring and failures diagnosis in a DFIG-based wind turbine. It has been proposed a combination of the Discrete Wavelet transform, statistics, and the energy. The carried out experiments on a $1.1-\mathrm{kW}$ induction generator based test bench have proved that a technique based on variance and energy analysis of wavelet decomposition stator current signals is very useful for condition monitoring and failure diagnosis in wind generators.

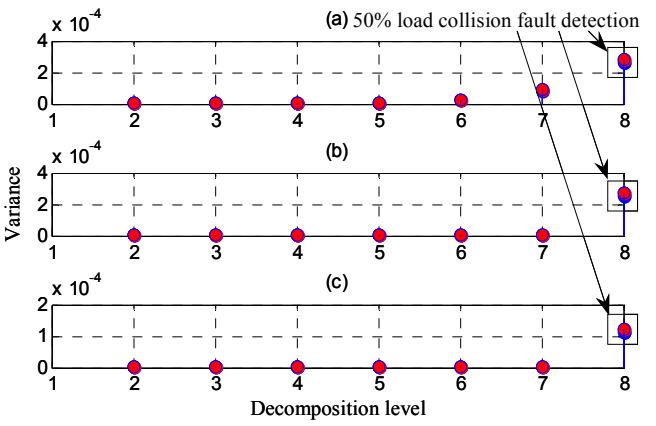

Fig. 11. Stator current detail levels variance: Healthy case (in bleu) and $50 \%$ load collision phenomenon (in red) using db1 (a), db5 (b) and dmey(c) wavelets.

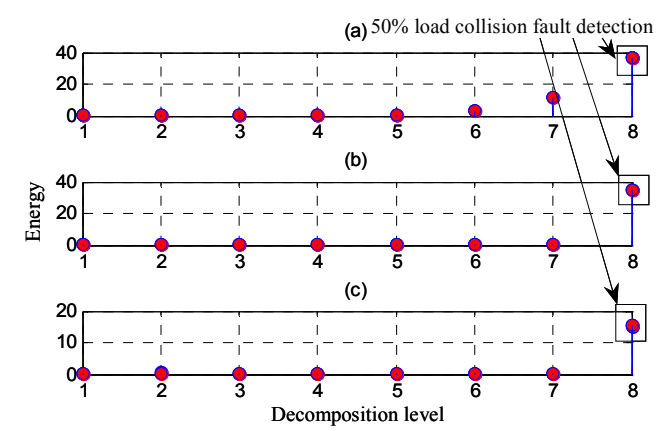

Fig. 12. Stator current detail levels energy: Healthy case (in bleu) and $50 \%$ load collision phenomenon (in red) using db1 (a), db5 (b) and dmey(c) wavelets. 
Proceedings of the 2008 International Conference on Electrical Machines

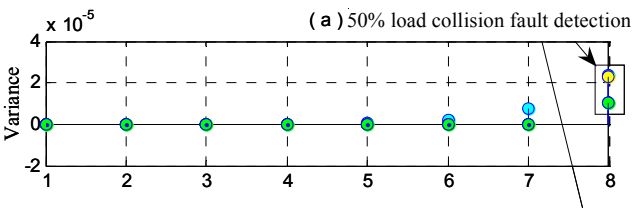

(b)

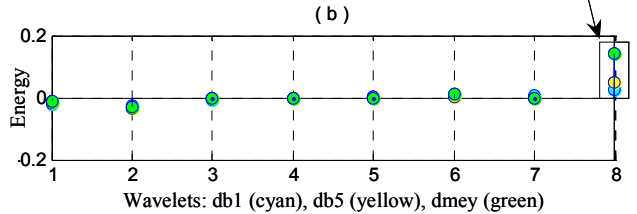

Fig. 13. Wavelets comparison for the detection and the diagnosis of a $50 \%$ load collision phenomenon.

\section{REFERENCES}

[1] R. Thresher et al., "The status and future of wind energy technology," IEEE Power \& Energy Magazine, vol. 5, n6, pp. 34-46, November/December 2007.

[2] D. McMillan et al., "Condition monitoring benefit for onshore wind turbines: sensitivity to operational parameters," IET Renewable Power Generation, vol. 2, n¹, pp. 60-72, March 2008.

[3] M.R. Wilkinson et al., "Towards the zero maintenance wind turbine," in Proceedings of the UPEC'06, vol. 1, pp. 74-78, Northumbria (UK), September 2006.

[4] L. Mihet-Popa et al., "Condition monitoring of wind generators," in Proceedings of IEEE IAS'03, vol. 3, pp 1839-1846, Salt Lake City (USA), October 2003.

[5] Z. Hameed et al., "Condition monitoring and fault detection of wind turbines and related algorithms: A review," Renewable and Sustainable Energy Reviews, (2007), doi:10.1016/j.rser.2007.05.008.

[6] M.E.H. Benbouzid et al., "Condition monitoring and fault diagnosis in wind energy conversion systems," in Proceedings of IEEE IEMDC'07, pp. 1434-1439, Antalya (Turkey), May 2007.

[7] M.E.H. Benbouzid et al., "The state of the art of generators for wind energy conversion systems," in Proceedings of ICEM'06, Chania (Greece), September 2006.

[8] M.E.H. Benbouzid, "A review of induction motors signature analysis as a medium for faults detection," IEEE Trans. Industrial Electronics, vol. 47, n 5 , pp. 984-993, October 2000.

[9] M.E.H. Benbouzid et al., "What stator current processing based technique to use for induction motor rotor faults diagnosis?," IEEE Trans. Energy Conversion, vol. 18, n², pp. 238-244, June 2003.

[10] J. Royo et al., "Machine current signature analysis as a way for fault detection in squirrel cage wind generators," in Proceedings of the IEEE SDEMPED'07, pp. 383-387, Cracow (Poland), September 2007.

[11] H. Douglas et al., "The detection of interturn stator faults in doubly-fed induction generators," in Proceedings of IEEE IAS'05, vol. 2, pp. 10971102, Hong Kong, October 2005.

[12] S. Nandi et al., "Condition monitoring and fault diagnosis of electrical motors - A review," IEEE Trans. Energy Conversion, vol. 20, n4, pp. 719-729, December 2005.

[13] W.Q. Jeffries et al., "Experience with bicoherence of electrical power for condition monitoring of wind turbine blades," IEE Proc. Vision, Image and Signal processing, vol. 145, n³, pp. 141-148, June 1998.

[14] R. Yacamini et al., "Monitoring torsional vibrations of electromechanical systems using stator currents," ASME Journal of Vibration \& Acoustics, vol. 120, pp. 72-79, 1998.

[15] M.R. Wilkinson et al., "Extracting condition monitoring information from a wind turbine drive train," in Proceedings of UPEC'04, vol. 1, pp. 591-594, Bristol (UK), 2004.

[16] M.R. Wilkinson et al., "Condition monitoring of wind turbine drive trains," in Proceedings of ICEM'06, Chania (Greece), September 2006.

[17] M.R. Wilkinson et al., "Condition monitoring of generators \& other subassemblies in wind turbine drive trains," in Proceedings of the IEEE SDEMPED'07, pp. 388-392, Cracow (Poland), September 2007.

[18] P. Caselitz et al., "Development of a fault detection system for wind energy converters," in Proceedings of EUWEC'96, pp. 1004-1007, Göteborg (Sweden), 1996.
[19] P. Caselitz et al., "Fault prediction techniques for offshore wind farm maintenance and repair strategies," in Proceedings of EWEC03, Madrid (Spain), June 2003.

[20] R. Datta et al., "Variable-speed wind power generation using doubly fed wound rotor induction machine-A comparison with alternative schemes," IEEE Trans. Energy Conversion, vol. 17, n³, pp. 414-421, September 2002.

[21] I. Albizu et al., "On-line stator winding fault diagnosis in induction generators for renewable generation," in Proceedings of IEEE MELECON'04, vol. 3, pp. 1017-1020, Dubrovnik (Croatia), May 2004.

[22] Q.F. Lu et al., "Model of stator inter-turn short circuit fault in doubly-fed induction generators for wind turbine," in Proceedings of IEEE PESC'04, vol. 2, pp. 932-937, Aachen (Germany), June 2004.

[23] P. Barendse al., "A new algorithm for the detection of inter-turn stator faults in doubly-fed wind generators," in Proceedings of the IEEE PESC'06, pp. 1235-1240, Paris (France), November 2006.

[24] A.H. Bonnet et al., "Cause and analysis of stator and rotor failures in three-phase squirrel-cage induction motors", IEEE Trans. Industry Applications, vol. 28, pp. 921-937, July-August 1992.

[25] S. Nandi et al., "Condition monitoring and fault diagnosis of electrical motors - A review," IEEE Trans. Energy Conversion, vol. 20, $\mathrm{n}^{\circ} 4$, pp. 719-729, December 2005.

[26] W.T. Thomson et al., "Current signature analysis to detect induction motor faults", IEEE Industry Applications Magazine, vol. 7, n 4 , pp. 2634, July/August 2001.

[27] M. Blodt et al., "On-line monitoring of mechanical faults in variablespeed induction motor drives using the Wigner distribution," IEEE Trans. Industrial Electronics, vol. 55, n², pp. 522-533, February 2008.

[28] L. Eren et al., "Bearing damage detection via wavelet packet decomposition of the stator current," IEEE Trans. Instrumentation \& Measurement, vol. 53, n², pp. 431-436, April 2004.

[29] K. Kim et al., "Induction motor fault diagnosis based on neuropredictors and wavelet signal processing," IEEE/ASME Trans. Mechatronics, vol. 7, n², pp. 201-219, June 2002.

[30] Y. Wenxian et al., "Condition monitoring and fault diagnosis of a wind turbine with a synchronous generator using wavelet transforms," in Proceedings of the IET PEMD'08, pp. 6-10, York (UK), April 2008.

[31] D. Shi et al., "Industrial applications of online machining process monitoring system," IEEE/ASME Trans. Mechatronics, vol. 12, n5, pp. 561-564, October 2007.

[32] L. Coppola et al., "Wavelet transform as an alternative to the short-time Fourier transform for the study of conducted noise in power electronics," IEEE Trans. Industrial Electronics, vol. 55, n², pp. 880-887, February 2008.

[33] C.S. Tsai et al., "Enhancement of damage-detection of wind turbine blades via CWT-based approaches," IEEE Trans. Energy Conversion, vol. 21, n³, pp. 776-781, September 2006.

[34] C. S. Burrus et al., Introduction to Wavelets and Wavelet Transforms. A Primer. Englewood Cliffs, NJ: Prentice-Hall, 1998.

[35] J.A. Antonino-Daviu et al., "Validation of a new method for the diagnosis of rotor bar failures via wavelet transform in industrial induction machines," IEEE Trans. Industry Applications, vol. 42, n 4, pp. 990-996, July/August 2006.

[36] M. Riera-Guasp et al., "The use of the wavelet approximation signal as a tool for the diagnosis of rotor bar failures," IEEE Trans. Industry Applications, vol. 44, n³, pp. 716-726, May-June 2008.

[37] J. Antonino-Daviu et al., "DWT analysis of numerical and experimental data for the diagnosis of dynamic eccentricities in induction motors," Mechanical Systems and Signal Processing, vol. 21, nº6, pp. 2575-2589, August 2007.

[38] J. Antonino-Daviu et al., "Application and optimization of the discrete wavelet transform for the detection of broken rotor bars in induction machines," Applied and Computational Harmonic Analysis, vol. 21, n², pp. 268-279, September 2007.

[39] R. Polikar, et al., "Frequency invariant classification of weld inspection signals, IEEE Trans. Ultrasonics, Ferroelectrics and Frequency Control, vol. 45, n³, pp.614-625, May 1998.

[40] T. Tarasiuk, "Hybrid wavelet-Fourier spectrum analysis," IEEE Trans. Power Delivery, vol. 19, n³, pp. 957-964, July 2004.

[41] A.P. Bradley et al., "On wavelet analysis of auditory evoked potentials," Clinical Neurophysiology, vol. 115, pp. 1114-1128, 2004. 